\title{
Research on determining reasonable negative pressure based on the control of the goaf
}

In order to study the law of spontaneous combustion in goaf under the condition of gas extraction, the method of beam tube monitoring and numerical analysis is adopted to obtain three dimensional distribution of oxygen concentration and contour map under the condition of different negative pressure. Based on the way of regression analysis, reasonable negative pressure are determined. The results show that with the increase of negative pressure, the spontaneous combustion "three-zone" in goaf: the heat dissipation zone and the spontaneous combustion zone become wider and the suffocation zone narrows. At the same time, the trend of spontaneous combustion zone presents to the deep part of the goaf; the amount of gas extraction increases first and then decreases with the increase of negative pressure. Combined with the trend of spontaneous combustion zone and the amount of gas extraction in goaf, and the reasonable negative pressure value is $32 \mathrm{kpa}$ and verified.

Keywords: Gas-drainage; spontaneous combustion in goaf; regression analysis; negative pressure.

\subsection{Introduction}

$\mathrm{G}$ as drainage in goaf is an important means to control gas overrun in upper corner of working face [1]. If the negative pressure is too low, the coal seam gas can not be effectively extracted, and the effect of extraction can not be achieved; if the negative pressure is too high,which results in the increase of air leakage in goaf, and have an induction for spontaneous combustion of residual coal, which is easy to cause spontaneous combustion in goaf. Therefore, selection of reasonable negative pressure is of great significance to coal mine safety production.

A great deal of research work has been carried out on spontaneous combustion of residual coal in goaf under different extraction conditions at home and abroad. According to the relevant application of theory, Song Wanxin [2] pointed

Blind peer reviews carried out

Messrs. Wang Yue-hong,Wu Yi, Zhang Jiu-ling and Ms. Li Zhi, College of Mining Engineering, North China University of Science and Technology, Tangshan Hebei 063009, China, Key laboratory of Mining Exploitation and Safety Technology in Hebei Province, Tangshan Hebei 063009. out that the division standard of "three-zone" for high gas coal seams is oxygen volume fraction based on the principle of chemical kinetics and applied in the field. Li Rifu [3] studied the effect law of different negative pressure on the gas flow field distribution in goaf and pointed out that the negative pressure of goaf can be reduced by controlling the negative pressure of drainage in a certain range. Li Shumin [4] shows that the effect of gas drainage in different areas is different through field test. However, most studies consider single disaster. Therefore, it is necessary to combine gas prevention with spontaneous combustion to explore reasonable negative pressure. In this paper, firstly, the field test and numerical analysis are used to compare to the changed law of spontaneous combustion "three-zone" in goaf under before and after extraction and different negative pressure. Then it combined with the effect of negative drainage pressure on the amount of gas extraction. Finally, it can obtain reasonable negative pressure value and verified. The research results provide a reference for determining reasonable extraction parameters and preventing spontaneous combustion in goaf

\subsection{General situation of working face}

$5877 Y$ working face are $U$ type ventilation in lvjiatuo coal mine of Kailuan Group. 5877Y working face is located in -800 mining area and the seven coal seam in this area belongs to I spontaneous combustion coal seam. The $5877 \mathrm{Y}$ working face is a longwall mining face, and the goaf are treated by means of caving. The length is $370 \mathrm{~m}$, the inclined length is $100 \mathrm{~m}$, the seam thickness is $2.75 \sim 4.2 \mathrm{~m}$, and the average thickness is $3.72 \mathrm{~m}$ in the seven coal seam in the $5877 \mathrm{Y}$ working face. The relative emission amount of gas and carbon dioxide in the working face is $1.23 \mathrm{~m}^{3} / \mathrm{t}$ and $1.85 \mathrm{~m}^{3} / \mathrm{t}$ respectively. The air supply amount of working face is $800 \mathrm{~m}^{3} / \mathrm{min}$, and the measured wind speed is $2.5 \mathrm{~m} / \mathrm{s}$ in roadway.

\subsection{Study on field experiment}

The first stage is not buried pipe drainage. The beam tube monitoring points are arranged at the upper corner and the lower corner of the 5877 working face, and there are four beam tube to lay. The beam tube must be hung and the steel tube with length of $70 \sim 100 \mathrm{~m}$ and diameter of $20 \mathrm{~mm}$ should be 
installed at the end of the bundle pipe to prevent the tube from being broken. The 2 beam pipe is laid from the return airway to the upper corner, and the monitoring points are arranged on the upper corner and near head-on position respectively. The other 2 road beam pipe is laid from the intake entry direction down corner, and the monitoring points are arranged on the lower corner and near head-on position. The arrangement of the measuring points should be adjusted simply by the beam pipe monitoring point at the time of the installation of the pipe bundle. The second stage is buried pipe drainage. When the working face of 5877 working face is pushed to a certain position, high position drilling is carried out for gas drainage. At the same time, the bundle tube is sheared at this position and set it to the monitoring point. Then it reinstall 70 100m drivepipe of which diameter is $20 \mathrm{~mm}$. Various gas indexes in goaf under different negative pressure are monitored again. The schematic diagram of beam tube laying is shown in Fig.1.

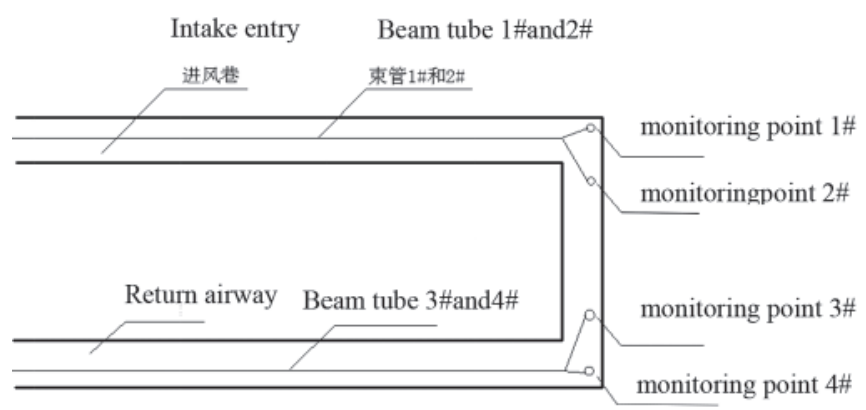

Fig.1: The diagram of tube installation

\subsection{Division of spontaneous combustion "three-zone" in goaf before drainage}

According to field observation data, it draws that broken line diagram and fitting image about four monitoring points of the working face to promote the distance and oxygen concentration changes

(1) It can be seen from Fig.2: With the increase of the distance between the working face, the oxygen concentration

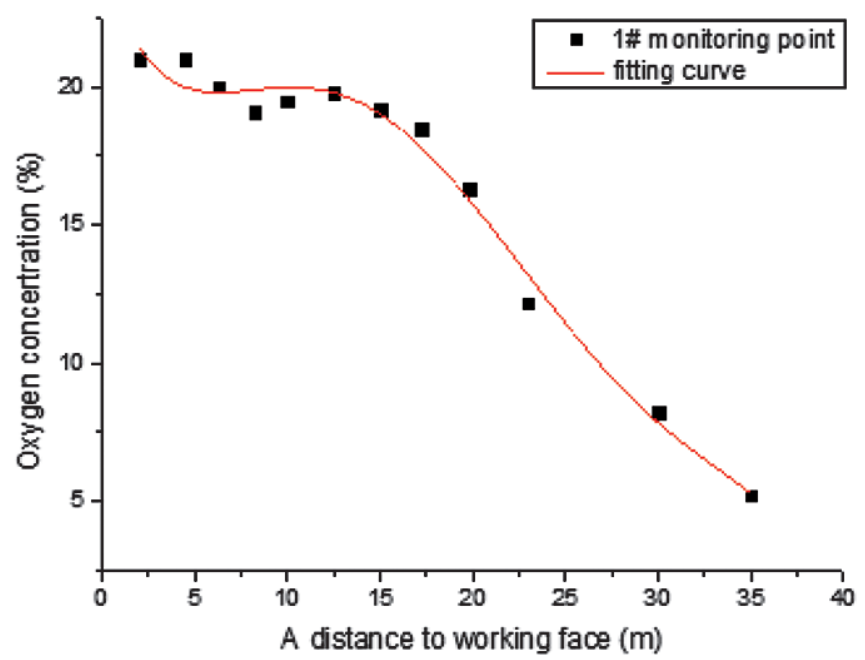

Fig. 2: $\mathrm{O}_{2}$ concentration variation curve at $1 \#$ monitoring point of the $1 \#$ monitoring point first decreases, and then decreases gradually after a small increase. Because $1 \#$ monitoring point is located in the intake entry position, the airflow enters from here, the residual coal consume oxygen in goaf. The roof as a good air leakage channel can effectively compensate for oxygen, so the oxygen concentration fluctuates with the advancing distance.

(2) It can be seen from Fig.5: With the increase of the distance between the working face, the oxygen concentration of the $4 \#$ monitoring point is decreasing. When the distance between the heat dissipation zone and suffocation belt was reached, the concentration of oxygen changed slowly. But when the distance of spontaneous combustion zone is pushed, the concentration of oxygen changes rapidly and decreases exponentially. It shows that the "three-zone" change is obvious in the return airway.

(3) It can be seen from Figs.3 and 4: With the increase of the distance between the working faces, the oxygen concentration of the $2 \#$ and $3 \#$ monitoring point showed a

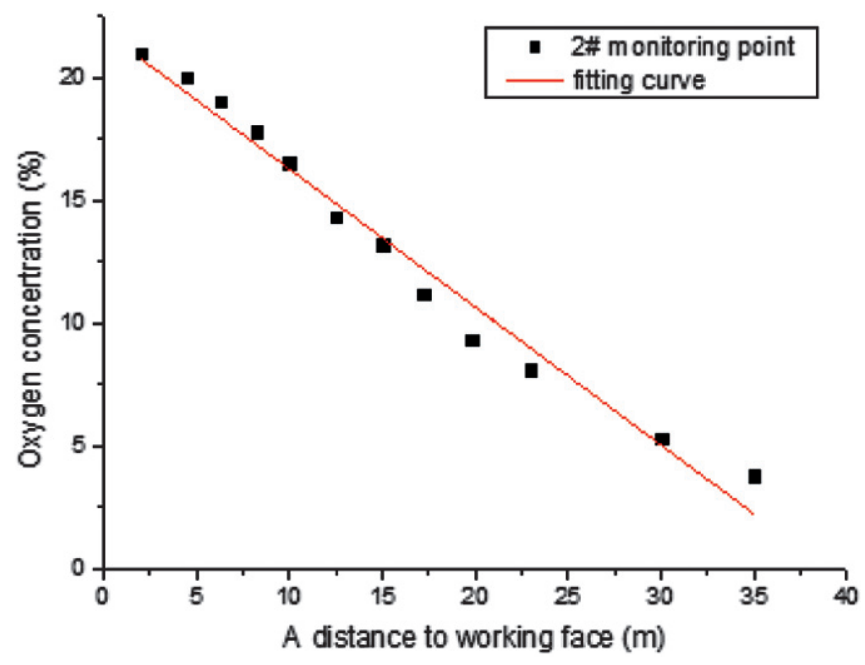

Fig.3: $\mathrm{O}_{2}$ concentration variation curve at $2 \#$ monitoring point

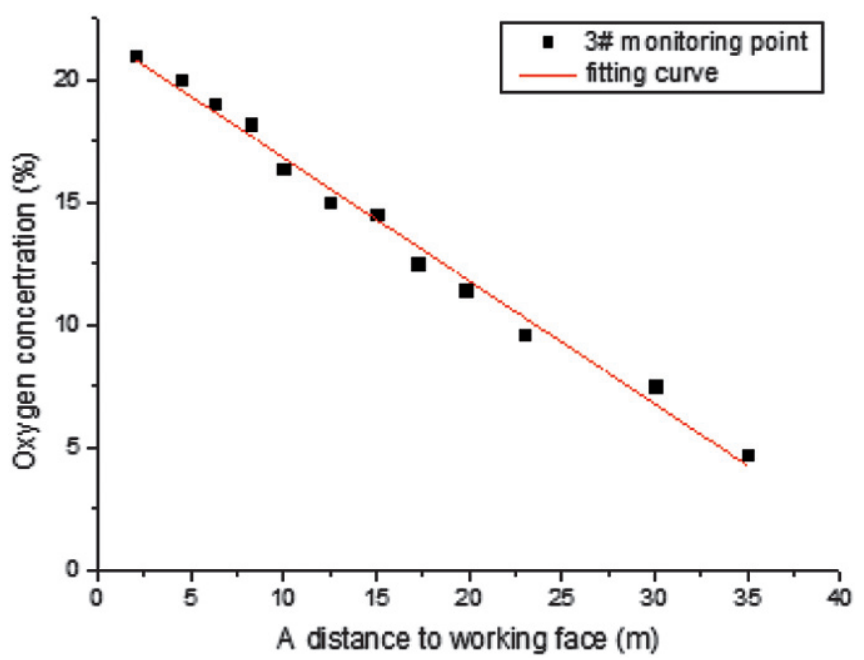

Fig.4: $\mathrm{O}_{2}$ concentration variation curve at $3 \#$ monitoring point 


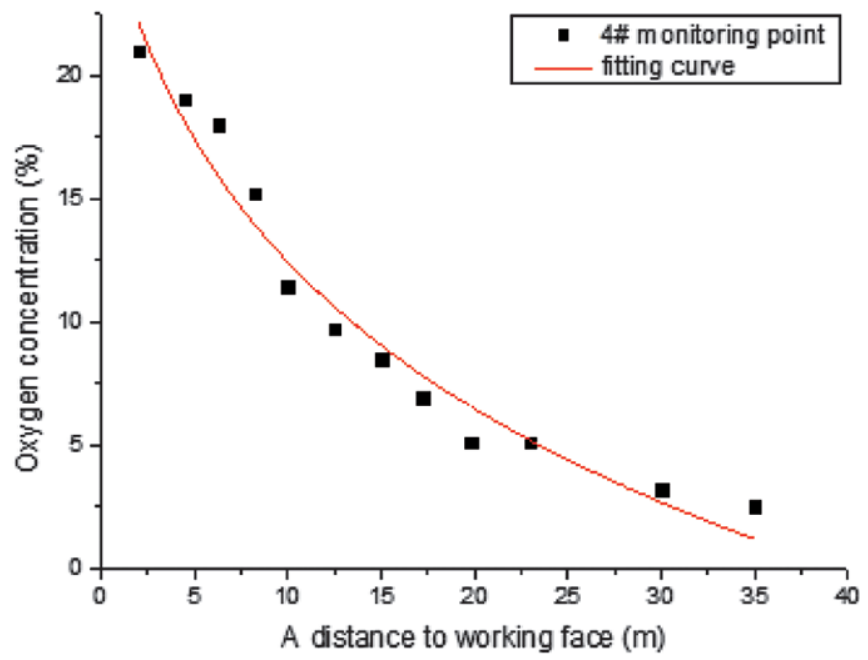

Fig.5: $\mathrm{O}_{2}$ concentration variation curve at $4 \#$ monitoring point

linear trend. Comparison with $1 \#$ monitoring points of the intake entry and $4 \#$ monitoring points of the return airway, $2 \#$ and $3 \#$ monitoring point is in the middle of the working face of the goaf. After the working face is pushed forward, the compaction state of the goaf is very good, which leads to the decrease of air leakage passage and the decrease of the rate of air leakage. The oxidation of the residual coal in the mined out area became worse, so the concentration of oxygen decreased linearly and rapidly.

According to the oxygen concentration in the goaf, the range of spontaneous combustion "three-zone" is drawn and the schematic diagram is drawn, as shown in Fig.6. And the maximum width of the spontaneous combustion zone is located in the middle of the goaf and the width is $14 \mathrm{~m}$. Obviously, the width of the spontaneous combustion zone on the taken entry is larger than on the return airway.

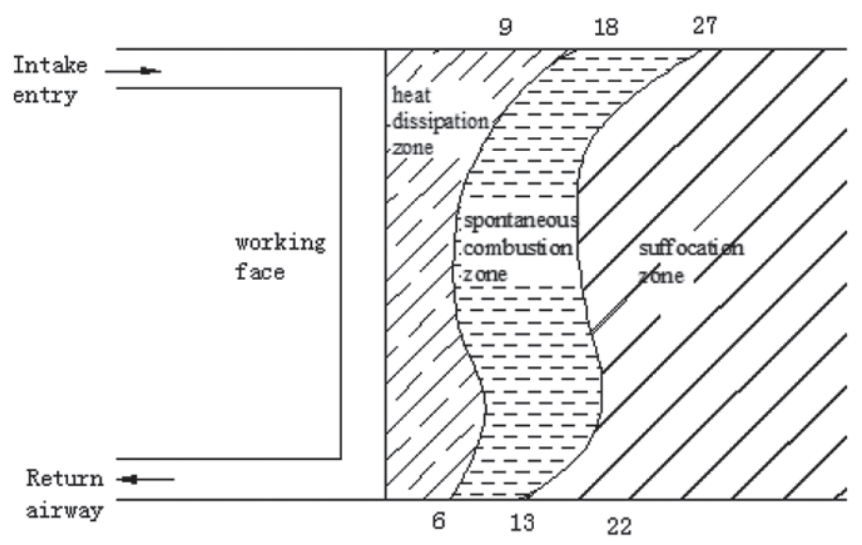

Fig.6: Distribution diagram of spontaneous combustion "three-zone" in goaf before extraction

\subsection{Determination of reasonable negative pressure}

5.1 INFLUENCE OF NEGATIVE PRESSURE ON SPONTANEOUS COMBUSTION "THREE-ZONE"

According to the data of field measured, the threedimensional distribution and contour map of oxygen concentration under different conditions of negative pressure are obtained by using Matlab software [5], as shown in Fig.7.

The oxygen concentration stereogram 7(a) can be seen before the extraction. With the consumption of oxygen in goaf of remaining coal, the concentration of oxygen decreased gradually along the goaf. When it reaches 40 meters, it has dropped to a lower level. As the air flow enters from the intake entry in goaf, after the loss of the residual coal in the goaf, the oxygen concentration is reduced when the return airway side is reached. The distribution range of spontaneous combustion "three-zone" in goaf can be seen from the contour map. It is obvious that the width of the suffocation belt is greater than that the heat dissipation zone and spontaneous combustion zone.

By adding different negative pressure, such as graph (b) (c) (d), compared to before pumping. The heat dissipation zone and the spontaneous combustion zone become wider, and the suffocation belt narrows, and the effect becomes more obvious with the increase of the negative pressure. When the negative pressure is $10 \mathrm{kpa}$, the spontaneous combustion zone of the intake entry side is about $15 \sim 35 \mathrm{~m}$ of the coal wall of the working face, and the spontaneous combustion zone on the return airway side is about $10 \sim 30 \mathrm{~m}$ away from the coal wall of the working face. When the negative pressure is $20 \mathrm{kpa}$, the spontaneous combustion zone of the intake entry side is about $20 \sim 40 \mathrm{~m}$ of the coal wall of the working face, and the spontaneous combustion zone on the return airway side is about $15 \sim 30 \mathrm{~m}$ away from the coal wall of the working face. When the negative pressure is $30 \mathrm{kpa}$, the spontaneous combustion zone of the intake entry side is about $23 \sim 58 \mathrm{~m}$ of the coal wall of the working face, and the spontaneous combustion zone on the return airway side is about $23 \sim 42 \mathrm{~m}$ away from the coal wall of the working face. Thus, the oxygen concentration in the intake entry side is very high, and the width of the spontaneous combustion zone on the intake entry side is larger than that on the return airway side.

The scope of spontaneous combustion zone is the key to the prevention and control of spontaneous combustion of residual coal in goaf. In order to analyze the influence of different negative pressure on the range of spontaneous combustion zone more directly, the broken line diagram of negative pressure and spontaneous combustion zone width is drawn, as shown in Fig.8. You can see from the graph that with the increase of negative pressure, the width of the spontaneous combustion zone increases in the middle of the goaf and the intake entry side and the width of the spontaneous combustion zone increases firstly and then becomes smaller in the return airway side.

\subsection{INFLUENCE OF NEGATIVE DRAINAGE PRESSURE ON GAS EXTRACTION}

According to the field measured data, the broken line diagram of negative pressure and gas extraction amount is 

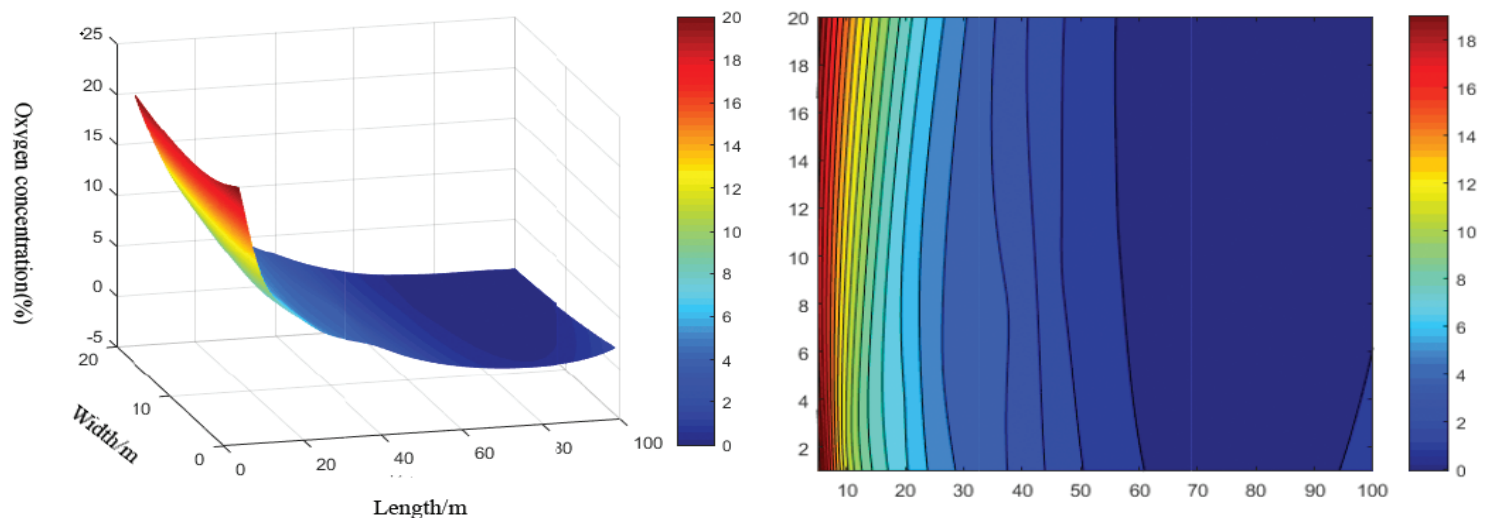

(a) $\mathrm{p}=0 \mathrm{kpa}$
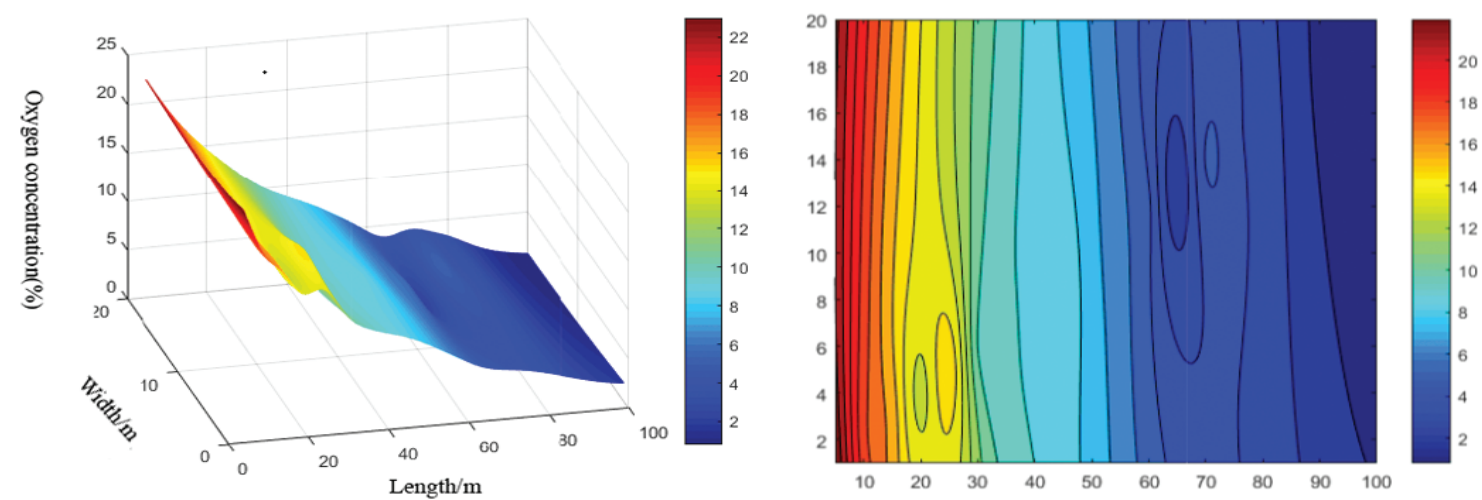

(b) $\mathrm{p}=10 \mathrm{kpa}$
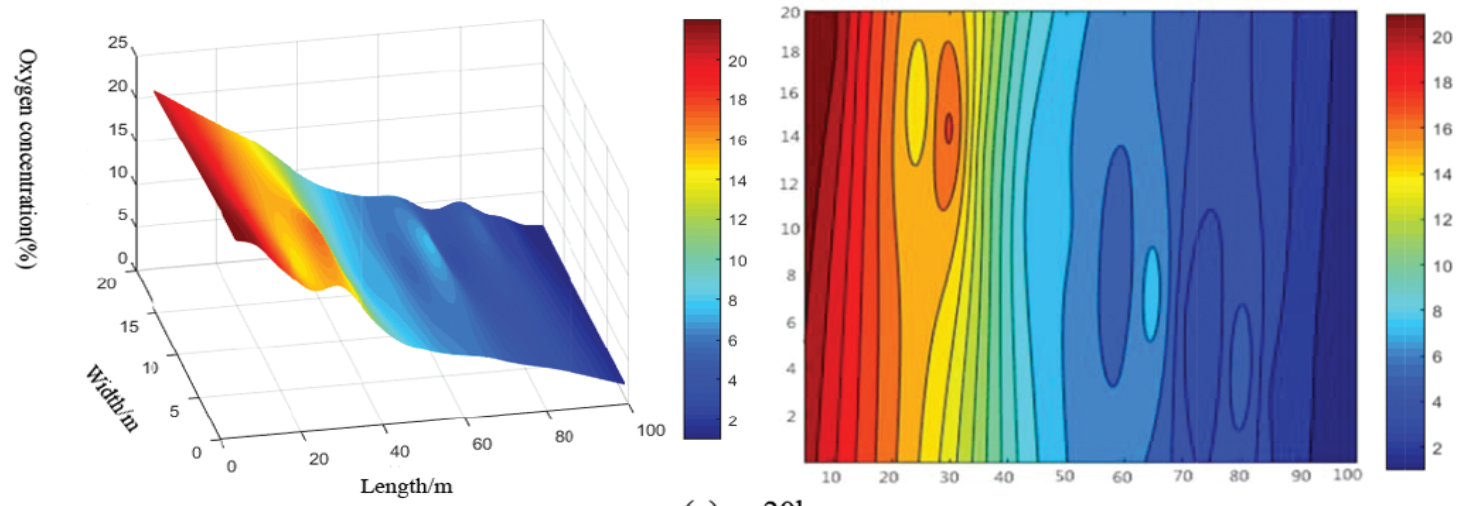

(c) $\mathrm{p}=20 \mathrm{kpa}$
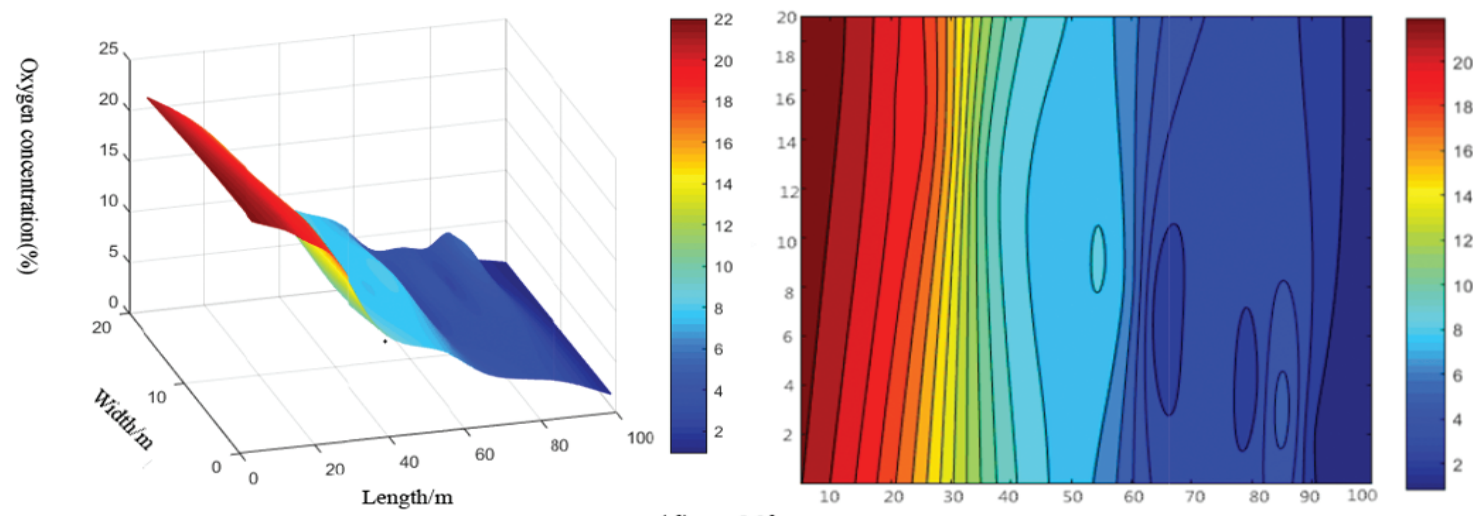

(d) $\mathrm{p}=30 \mathrm{kpa}$

Fig.7: Oxygen concentration distribution and contour map under different pumping negative pressure conditions 


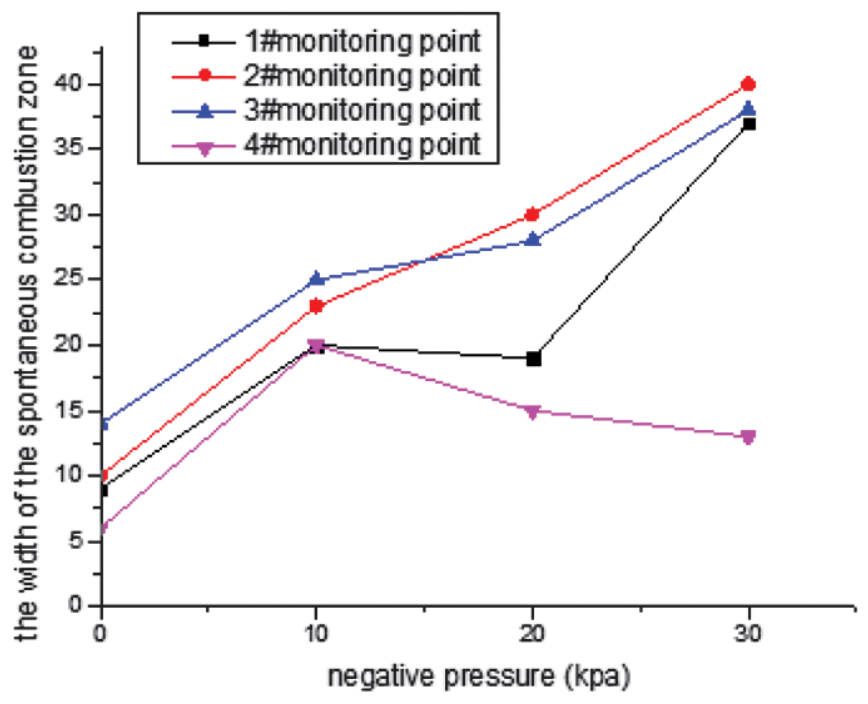

Fig. 8 Relationship between the width of spontaneous combustion zone and the variation of negative pressure

drawn by using Origin software, as shown in Fig.9. As you can see from the graph, with the increase of suction pressure, the gas extraction amount increases first and then decreases. When the suction pressure is $45 \mathrm{kpa}$, the gas extraction amount reaches the maximum value.

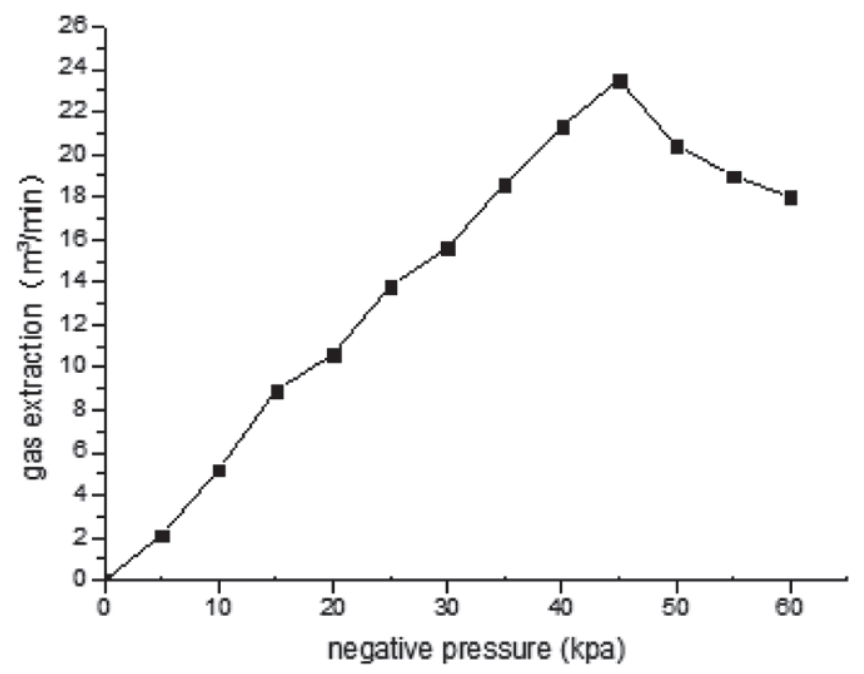

Fig.9: Relationship between negative pressure and gas extraction

\subsection{REGRESSION ANALYSIS}

In order to study gas drainage and spontaneous combustion of residual coal in goaf comprehensively. The regression analysis [6] of the relationship between the width of spontaneous combustion belt and gas extraction is carried out by negative pressure. The independent variable $x$ is defined as pumping negative pressure. $y_{1}$ is the width of spontaneous combustion zone in the return airway side, $y_{2}$ is the width of spontaneous combustion zone in the middle return airway side, $y_{3}$ is the width of spontaneous combustion zone in the central intake entry side, $y_{4}$ is the width of spontaneous combustion zone in the intake entry side, and $y_{5}$ is the gas extraction flow rate.

According to the field experiment, it can obtain that the relationship between the negative pressure and the width of spontaneous combustion zone and gas extraction, the curve regression model is established, as is shown in formula 1.

$y=a x^{3}+b x^{2}+c x+d$

Calculated by using SPSS software, the regression equation is as follows:

$$
y_{1}=0.003 x_{1}^{3}-0.19 x_{1}^{2}+2.844 x_{1}+6.548
$$

Calculated in turn, the regression equation is as follows:

$$
\begin{aligned}
& y_{2}=0.002 x_{2}^{3}-0.081 x_{2}^{2}+1.653 x_{2}+14.524 \\
& y_{3}=0.002 x_{3}^{3}-0.108 x_{3}^{2}+2.233 x_{3}+10.286 \\
& y_{4}=0.003 x_{4}^{3}-0.129 x_{4}^{2}+1.940 x_{4}+8.476 \\
& y_{5}=(-2.790 E-005) x_{5}^{3}-0.006 x_{5}^{2}+0.797 x_{5}-1.371 \ldots
\end{aligned}
$$

Using mathematics software is to calculate the extreme value [7]. The calculation results indicate that when $x$ is greater than 0 and less than $50, x_{1}$ is equal to $32 \mathrm{kpa}, y_{1 \min }$ is equal to $2.5709 \mathrm{~m}$; $x_{2}$ is equal to $0 \mathrm{kpa}, \mathrm{y}_{2 \mathrm{~min}}$ is equal to $14.524 \mathrm{~m}$; $x_{3}$ is equal to $0 \mathrm{kpa}, y_{3 \min }$ is equal to $10.286 \mathrm{~m} ; x_{4}$ is equal to $0 \mathrm{kpa}, y_{4 \mathrm{~min}}$ is equal to $8.476 \mathrm{~m} ; x_{5}$ is equal to $50 \mathrm{kpa}, y_{5 \max }$ is equal to $20.4 \mathrm{~m}^{3} / \mathrm{min}$.

By comparing the magnitude of each extreme point, it can obtain the minimum width of spontaneous combustion zone is in the return airway side. So $x$ is selected greater than 32 and less than 50, make $y_{1}$ and $y_{5}$ difference calculate, as shown in formula 7. By calculating the maximum of the $\beta$, the greater the $y_{5}$ (gas extraction), the smaller the width of $y_{1}$ (spontaneous combustion zone in goaf), it obtains $x$ is equal to $32 \mathrm{kpa}$.

$$
y_{5}-y_{1}=\beta
$$

\subsection{VERIFY THE REASONABLE NEGATIVE PRESSURE}

(1) According to the measured data, it can obtain the equation of the relationship between gas concentration of the intake entry and negative pressure through linear analysis. As is shown in formula 8 .

$$
C_{1}=-0.021 p_{1}+0.959
$$

The relationship equation of gas concentration of the return airway and negative pressure is shown in formula 9.

$$
C_{2}=-0.026 p_{2}+0.894
$$

According to the coal mine safety regulations, defined as gas concentration in the return airway is less than $1 \%$, gas concentration in the intake entry required for not more than $0.5 \%$ [8]. Combined with the actual situation of the scene, the gas concentration cannot reach the safety limit value. Thus it must give a coefficient, taking $\beta$ is 1.5 . The maximum value of gas concentration in return airway is shown in formula 10 .

$$
C_{\max }^{1}=\frac{1.0 \%}{\beta}=\frac{1.0 \%}{1.5}=0.67 \%
$$


The maximum value of gas concentration in the intake entry is shown in formula 11.

$$
C_{\max }^{2}=\frac{0.5 \%}{\beta}=\frac{0.5 \%}{1.5}=0.34 \%
$$

According to the formula (9), the minimum negative pressure that can be calculated from gas concentration in return airway less than $1 \%$ is $21 \mathrm{kpa}$. According to the formula (8), the minimum negative pressure that can be calculated from gas concentration in intake entry less than $0.5 \%$ is $13 \mathrm{kpa}$. Based on the above analysis, the range of negative pressure is greater than $21 \mathrm{kpa}$.

(2) According to the theory of spontaneous combustion, when the remaining coal in the spontaneous combustion zone exists more than the shortest period of spontaneous combustion, the residual coal will occur spontaneous combustion. The maximum width of spontaneous combustion zone is shown in formula 12.

$$
L_{\text {max }}=v \cdot t
$$

$v$ is the propulsion speed, its unit is $\mathrm{m} / \mathrm{d} ; t$ is the shortest spontaneous combustion period, its unit is $d$.

The propulsion speed of $5877 \mathrm{Y}$ working face is $1.2 \mathrm{~m} / \mathrm{d}$, the shortest spontaneous combustion period is $60 \mathrm{~d}$. It can calculate the maximum width of spontaneous combustion zone is 72 .

According to the actual situation, it must give propulsion speed a coefficient, taking $\theta$ as 1.2 . The maximum width of spontaneous combustion zone is shown in formula 13.

$$
L_{\text {max }}^{\prime}=\frac{v \cdot t}{\theta}=60
$$

When the width of spontaneous combustion zone in intake entry side of the goaf is $60 \mathrm{~m}$, the negative pressure of drainage that can be calculated is $46 \mathrm{kpa}$ from formula 5 . Therefore, the negative pressure of drainage of remaining coal spontaneous combustion in goaf is less than $46 \mathrm{kpa}$.

(3) In summary, the analysis shows that the safe range of negative pressure for $5877 \mathrm{Y}$ working face in lvjiatuo coal mine of Kailuan Group is greater than 21 and less than 46. Because the $32 \mathrm{kpa}$ is in the safe range, the negative pressure is reasonable.

\subsection{Conclusions}

1. According to the measured data and the division index of oxygen concentration, it can obtain the range of spontaneous combustion "three-zone" in goaf and the range and distribution of spontaneous combustion "three-zone" at each measuring point.

2. Although using of Matlab software, it generate oxygen concentration of three-dimensional distribution of mining and contour map under different negative pressure condition. The variation of spontaneous combustion "three-zone" is compared to before and after extraction and the negative pressure increasing. That is, the spontaneous combustion zone and the cooling band become wider and wider, and the suffocation zone becomes narrower and narrower. And with the increase of negative pressure, the width of the spontaneous combustion zone in the return airway first increases and then decreases. The width of the spontaneous combustion zone in the intake entry side and the middle part of the goaf increases with the increase of negative pressure.

4. The negative pressure is coupled with the width of spontaneous combustion zone and the amount of gas extraction. Based on regression analysis method, the equation corresponding to the minimum are found and made the difference. The reasonable suction negative pressure value is calculated to be $32 \mathrm{kpa}$ and verified.

\section{Acknowledgements}

This work was supported by national natural fund project (51404086, 51504077), Hebei natural science foundation funding project (E2016209056) and outstanding youth fund of north China university of technology (jp201509).

\section{Reference}

1. Ran Y J. (2014): Research on Reasonable Ne-gative Pressure in Gas Drainage Syste-m for No.2-1 Coal Seam of Jiu Lish-an mine.Henan Polytechnic Universit-y.

2. Song W X, Yang S Q, Xu Q. (2012): Divisio-n of Spontaneous Combustion "Three-Zone" in High-Gas Goaf Based on O-xygen Concentration. Journal of mining and safety engineering, 29(02) : 271-276.

3. Li Rifu ( 2012): Negative Pressure of Gas Dr-ainage Well at Surface Affected to Di-stribution of Gas Flow Filed in Goaf.Coal science and technology, 40(07) : 38$40+88$.

4. Li S M (2017): Study on the influence of the pumping effect of negative pressure on the coal seam gas. Energy Technology and Management, 42(03) : 30$31+36$.

5. Yu M G, Chang X H, Jia H L, Lu L X (2010): Analysis of spontaneous combusti-on"three-zone" in goaf based on Mat-lab. Journal of china coal society, 35(04) : 600-604.

6. Cheng W M, Sun L L, Zhang X Q. (2012): Study on the characteristics of fully mechanized working face based on ox-ygen concentration distribution spontaneous combustion "three-zone" in goa-f. Mining safety and environmental protection, 39(05): 7-10+99.

7. Lan Z Q, Zhang G K, Wang Z L, M-a H P. (2008): Research on "Three-Zone" Di-stribution of Goaf with Gas Discharg-e Laneway. Safety in coal mines, (11):1-4.

8. Yu M G, Yao J K, Jia H L (2013): Compre-hensive dividing method and practice of spontaneous combustion "three-zone" in goaf on fully mechanized coal face. Journal of Henan University (naturescience edition), 32(02) : 131-135+150. 